\title{
LC-MS/MS METHOD FOR THE DETERMINATION OF DIAZOLIC ANTHELMINTIC DRUG LEVELS FROM SHEEP AND HUMAN PLASMA FOR USE IN PHARMACOKINETIC AND BIOAVAILABILITY STUDIES
}

\author{
LÉNÁRD FARCZÁDI ${ }^{\mathrm{a}, \mathrm{b}}$, SILVIA IMRE ${ }^{\mathrm{b}, \mathrm{c}^{*}}$, LAURIAN VLASE ${ }^{\mathrm{a}}$
}

\begin{abstract}
A new high-throughput, inexpensive and selective LC-MS method for determining fenbendazole, albendazole and albendazole sulfoxide from human and ovine plasma was developed and validated in accordance with current guidelines in bioanalysis. Analytes (fenbendazole, albendazole, albendazole sulfoxide) and internal standard (fluconazole) were separated on a Gemini NX-C18 analytical column in reversed phase chromatography in gradient elution using mobile phase composed of acetonitrile and aquenous $0.2 \%$ formic acid with a flow rate of $0.6 \mathrm{~mL} / \mathrm{min}$. After positive electrospray ionization analytes were detected in the mass spectrometer in selected reaction monitoring mode, monitoring fragment ion $\mathrm{m} / \mathrm{z} 268.05 \mathrm{from} \mathrm{m} / \mathrm{z}$ 300.08 for fenbendazole, ion $\mathrm{m} / \mathrm{z} 234.07$ from m/z 266.09 for albendazole, ion $\mathrm{m} / \mathrm{z} 240.04 \mathrm{from} \mathrm{m} / \mathrm{z} 282.09$ for albendazole sulfoxide and ion $\mathrm{m} / \mathrm{z} 220.06$ from m/z 307.60 for fluconazole. Sample preparation was performed using protein precipitation. Validation of the analytical method was performed with respect to selectivity, stability, linearity ( $r>0.9901)$, precision (RSD<12.9\%) and accuracy (bias $<12.7 \%$ ) over the concentration ranges of $5-250 \mathrm{ng} / \mathrm{mL}$ for each analyte (lower limit of quantification was $5 \mathrm{ng} / \mathrm{mL}$ for all analytes). The analytical method is simple, versatile and suitable for bioanalysis of these azole anthelmintic drugs from human and ovine samples, and applicable in pharmacokinetic studies involving fenbendazole and albendazole.
\end{abstract}

Keywords: fenbendazole, albendazole, pharmacokinetics, bioavailability, LC-MS

\footnotetext{
a Iuliu Hatieganu University of Medicine and Pharmacy, Faculty of Pharmacy, Department of Pharmaceutical Technology and Biopharmaceutics, 8 Victor Babes street, RO-400012, ClujNapoca, Romania

b George Emil Palade University of Medicine, Pharmacy, Science, and Technology of Targu Mures, Center for Advanced Medical and Pharmaceutical Research, 38 Gheorghe Marinescu street, RO-540142, Targu Mures, Romania

c George Emil Palade University of Medicine, Pharmacy, Science, and Technology of Targu Mures, Faculty of Pharmacy, Department of Analytical Chemistry and Drug Analysis, 38 Gheorghe Marinescu str., RO-540142, Targu Mures, Romania

*Corresponding author, email: silvia.imre@umfst.ro
} 


\section{INTRODUCTION}

Albendazole and fenbendazole are two broad-spectrum benzimidazolic anthelmintics. They are both used in the treatment of a wide array of parasitic worm infections [1]. Benzimidazole anthelmintics hinder the development of nematodes by interfering in important structural as well as other functions. This is accomplished by inhibiting synthetization of microtubules, and in the case of some species even through an ovicidal effect.

Fenbendazole is currently used around the world for treating livestock, pets and other animals for helminthic infections and its safety has been well assessed over the more than three decades since its being used. Fenbendazole, although currently not used for anthelmintic treatment in humans, based on limited data has been shown to be safe for human in doses up to $500 \mathrm{mg}$ or even $2000 \mathrm{mg}$, with no adverse effects being reported.

Fenbendazole is absorbed only in limited quantities in the intestine after oral administration and is rapidly metabolized by liver microsomes to oxfendazole through sulfoxidation. This metabolism step however is reversible and can lead to the formation of fenbendazole. Studies have also shown promising antitumor effects of fenbendazole in mice when combined with certain supplementary vitamins which in the future might lead to further research and a possible new application of fenbendazole in humans [2].

Albendazole has also been widely used to treat humans with helmintic infections, but also animals such as livestock and pets [3], and is also one of the drugs listed on the WHO's Essential Drugs-list [4]. Toxicity of albendazole is low after oral adminstration, resulting in low plasma levels of albendazole because of rapid metabolization by liver microsomes to its sulfoxilated metabolite, albendazole sulfoxide, which is further metabolized to albendazole sulfone [3].

It is thought that both enzymes CYP3A4 and CYP2C19, along with other cytochrome P450 isoforms are responsible for the formation of sulfoxide metabolites from albendazole and fenbendazole [5]. Thus, albendazole and fenbendazole may be susceptible to drug-drug interactions if combined with inhibitors of these enzymes, such as for example fluconazole. This might be essential for example, as pointed out by the authors of the study discovering possible antitumor effects of fenbendazole [2], if fenbendazole is to be used in the treatment of cancer, in which case studies investigating drug interactions of fenbendazole with inhibitor drugs of CYP3A4 and other cytochrome P450 isoforms, as well as further bioavailability and other preclinical and clinical studies will need to be carried out on both on laboratory animals as well as human subjects.

Currently there are methods described in literature for the quantification of fenbendazole and albendazole, as well as some of their metabolites from 
different types of biological samples, most often plasma, collected from both human subjects as well as a number of different species of animals [6-13]. Most of the methods described use LC-MS/MS methodologies due to the advantage this technique offers with regards to improved selectivity and sensitivity [6-10]. There have also been methods developed and described in literature which use liquid chromatography with UV or fluorescence detection [11-13].

The study was conducted in order to propose a simple, versatile and reliable analytical method suitable for high-throughput bioavailability, biomonitoring, bioequivalence or other types of clinical studies using a simple, fast and inexpensive sample preparation method, short analytical runtime and with performance parameters validated according to current guidelines in bioanalysis.

\section{RESULTS AND DISCUSSION}

The proposed method was fully validated according to FDA (Food and Drug Administration, USA) [14] and EMA (European Medicines Agency) [15] bioanalytical method validation guidelines.

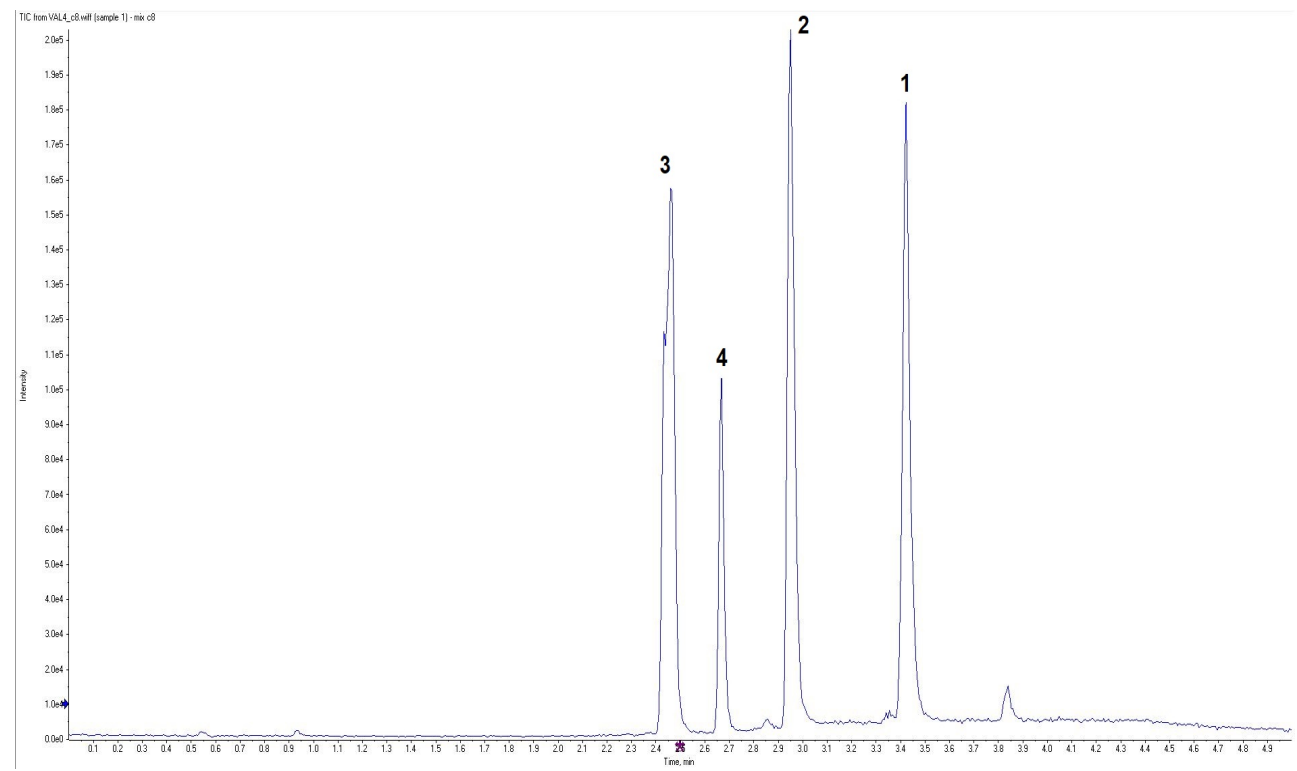

Figure 1. The Total lon Chromatogram (TIC) of a standard solution containing fenbendazole (1), albendazole (2), albendazole sulfoxide (3) and fluconazole (4) 
Under optimal mass spectrometer parameters and chromatographic conditions, the three analytes were detected using selected reaction monitoring (SRM): fenbendazole - ion $\mathrm{m} / \mathrm{z} 268.05$ from m/z 300.08; albendazole - ion $\mathrm{m} / \mathrm{z}$ 234.07 from m/z 266.09; albendazole sulfoxide - ion $\mathrm{m} / \mathrm{z} 240.04$ from m/z 282.09; fluconazole - ion $\mathrm{m} / \mathrm{z} 220.06$ from m/z 307.60. Retention times were 3.4 minutes for fenbendazole, 2.9 minutes for albendazole, 2.5 minutes for albendazole sulfoxide and 2.7 minutes for the internal standard (fluconazole), all compounds being separated at individual retention times (Figure 1).

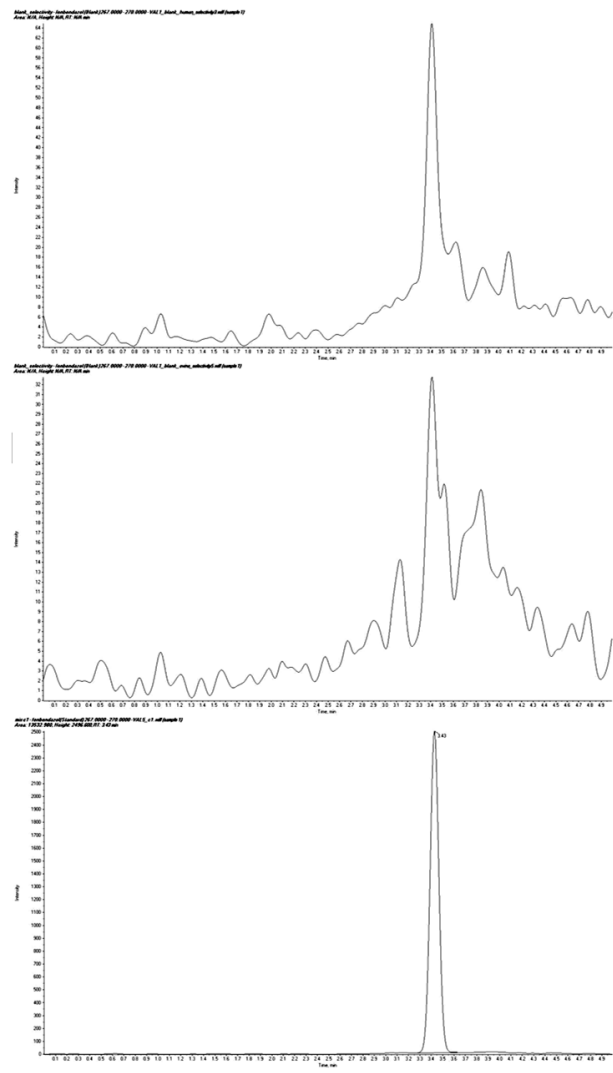

a)

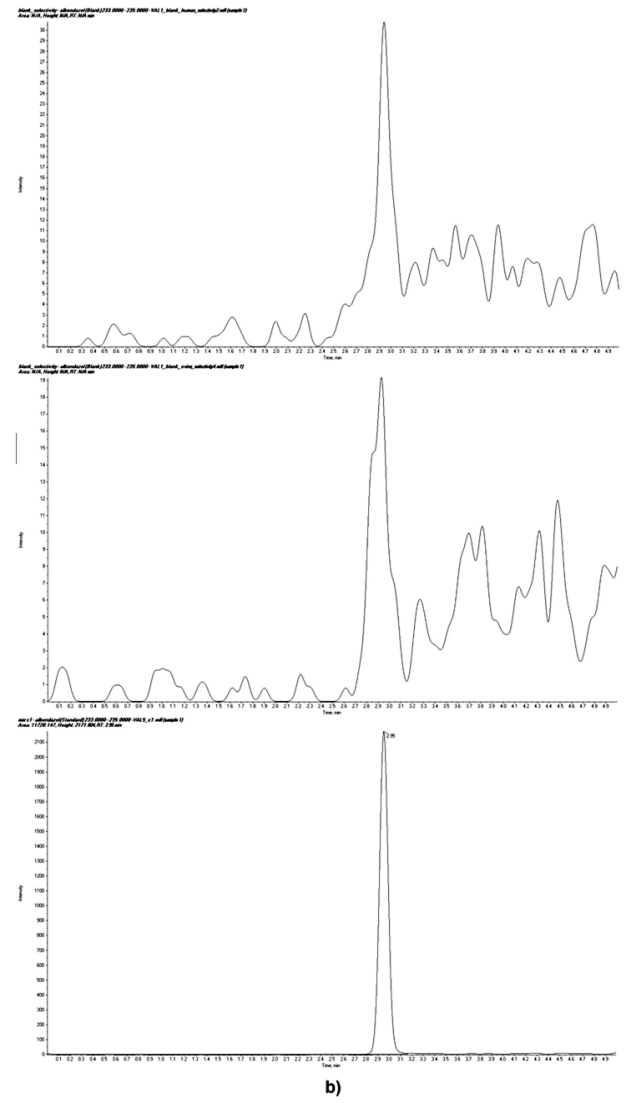

b)

Figure 2. Extracted chromatograms of human blank plasma (top), ovine blank plasma (middle) and standard solution at the lower limit of quantification (bottom) for a) fenbendazole, b) albendazole 

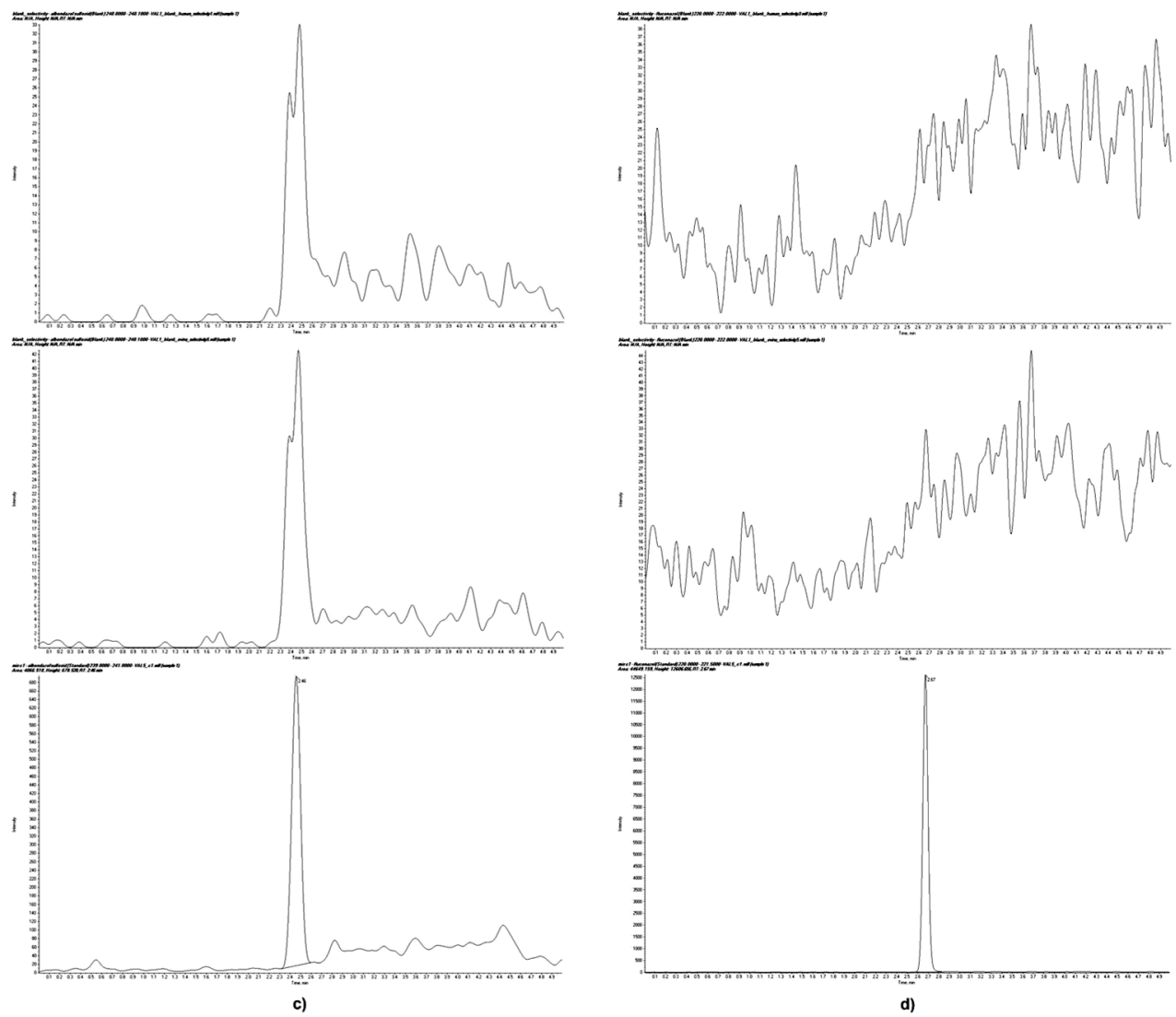

Figure 2. Extracted chromatograms of human blank plasma (top), ovine blank plasma (middle) and standard solution at the lower limit of quantification (bottom) for $\mathrm{c}$ ) albendazole sulfoxide, d) fluconazole (internal standard)

\section{Selectivity}

The analytical method needs to distinguish the analytes and IS from endogenous compounds from the biological matrix (plasma) or other compounds which may be present in biological samples. For all six different blank samples tested, no interfering peaks with a peak area greater than $20 \%$ of analyte peak area at the lower limit of quantification (LLOQ) were detected (Figure 2). Results for selectivity testing are presented in Table 1. 
Table 1. Selectivity for fenbendazole, albendazole and albendazole sulfoxide

\begin{tabular}{|c|c|c|c|}
\hline Analyte & $\begin{array}{c}\text { Mean } \\
\text { Blank Area }\end{array}$ & LLOQ Area & $\begin{array}{c}\text { Selectivity } \\
(\mathbf{\%})\end{array}$ \\
\hline Fenbendazole & 157.08 & 16826.62 & 99.07 \\
\hline Albendazole & 122.80 & 15888.64 & 99.23 \\
\hline Albendazole sulfoxide & 96.18 & 2800.81 & 96.57 \\
\hline
\end{tabular}

\section{Carry-over}

The carry-over effect (contamination from one sample to the next) was studied by injecting a blank solution immediately after the most concentrated standard solution ( $250 \mathrm{ng} / \mathrm{mL}$ of each analyte) in each run of the validation. Carry-over was below $20 \%$ of LLOQ areas for analytes and below $5 \%$ of IS area. Results are presented in Table 2.

Table 2. Carry-over for fenbendazole, albendazole, albendazole sulfoxide and fluconazole (ISTD)

\begin{tabular}{|c|c|c|c|}
\hline Analyte & $\begin{array}{c}\text { Mean } \\
\text { Blank Area }\end{array}$ & LLOQ Area & $\begin{array}{c}\text { Carry-over } \\
\text { (\%) }\end{array}$ \\
\hline Fenbendazole & 1338.75 & 14149.38 & 9.68 \\
\hline Albendazole & 0.0 & 12215.70 & 0.0 \\
\hline Albendazole sulfoxide & 0.0 & 3402.30 & 0.0 \\
\hline Fluconazole (ISTD) & 0.0 & 49783.52 & 0.0 \\
\hline
\end{tabular}

\section{Linearity and lower limit of quantification}

Calibration curves proved to be linear over the proposed concentration range with a LLOQ of $5 \mathrm{ng} / \mathrm{mL}$ for each analyte. The accuracy of recalculated concentrations of calibration standards was within acceptance limits for all calibration curves and all analytes, with no single calibration curve being compiled of less than 7 calibration standards which have passed acceptance criteria. Mean calibration curves characteristics for fenbendazole, albendazole and albendazole sulfoxide are presented in Table 3. Five standard solutions at the LLOQ of $5 \mathrm{ng} / \mathrm{mL}$ of each analyte were analyzed in order to determine within and between run accuracy and precision (Tables 4-5) at this level of concentration. 
Table 3. Characteristics of calibration curves, $n=5$

\begin{tabular}{|c|c|c|c|c|}
\hline Analyte & $\begin{array}{l}\text { Conc. } \\
\text { range, } \\
\text { ng/mL }\end{array}$ & Slope \pm SD & Intercept \pm SD & $\begin{array}{c}\text { Correlation } \\
\text { coefficient } \\
\text { range }\end{array}$ \\
\hline Fenbendazole & \multirow{3}{*}{$5-250$} & $\begin{array}{c}0.0198 \pm \\
0.0033\end{array}$ & $\begin{array}{c}0.1905 \pm \\
0.0375\end{array}$ & 0.9943-0.9992 \\
\hline Albendazole & & $\begin{array}{c}0.0199 \pm \\
0.0030\end{array}$ & $\begin{array}{c}0.1529 \pm \\
0.0417\end{array}$ & 0.9953-0.9973 \\
\hline $\begin{array}{l}\text { Albendazole } \\
\text { sulfoxide }\end{array}$ & & $\begin{array}{c}0.0068 \pm \\
0.0018\end{array}$ & $\begin{array}{c}0.0331 \pm \\
0.0118\end{array}$ & $0.9901-0.9943$ \\
\hline
\end{tabular}

\section{Accuracy and precision}

The results are presented in Tables 4-5. Mean accuracy and precision were within $\pm 15 \%$ acceptance limit for each analyte, both within as well as between runs.

Table 4. Overall within-run accuracy and precision ranges for fenbendazole, albendazole and albendazole sulfoxide at LLOQ, QCA, QCB and QCC levels

\begin{tabular}{|c|c|c|}
\hline Analyte & $\begin{array}{c}\text { Avg. accuracy range } \\
\text { (\% bias) }\end{array}$ & $\begin{array}{c}\text { Avg. precision range } \\
\text { (\% RSD) }\end{array}$ \\
\hline Fenbendazole & $-4.8 \div+8.2$ & $5.5 \div 12.9$ \\
\hline Albendazole & $-3.4 \div+10.1$ & $5.8 \div 8.7$ \\
\hline Albendazole sulfoxide & $-2.7 \div+11.0$ & $4.3 \div 7.0$ \\
\hline
\end{tabular}

Table 5. Overall between-run accuracy and precision ranges for fenbendazole, albendazole and albendazole sulfoxide at LLOQ, QCA, QCB and QCC levels

\begin{tabular}{|c|c|c|}
\hline Analyte & $\begin{array}{c}\text { Avg. accuracy } \\
\text { (\% bias) }\end{array}$ & $\begin{array}{c}\text { Avg. precision } \\
\text { (\% RSD) }\end{array}$ \\
\hline Fenbendazole & $-9.3 \div+8.1$ & $2.1 \div 6.2$ \\
\hline Albendazole & $-8.5 \div+10.6$ & $2.5 \div 9.4$ \\
\hline Albendazole sulfoxide & $-4.9 \div+12.7$ & $3.6 \div 8.2$ \\
\hline
\end{tabular}

\section{Stability}

Extensive stability testing was carried out to determine the stability of analytes and internal standard in different conditions, using quality control plasma samples (lower and higher QC samples). Long term stability, short term stability, auto-sampler stability, freeze-thaw stability and stability of stock, working and IS solutions stability were studied. Results for average quality control sample accuracies in stability testing of each analyte are presented in Table 6. 
Table 6. Stability of fenbendazole, albendazole and albendazole sulfoxide

\begin{tabular}{|c|c|c|}
\hline \multirow{4}{*}{ Analyte } & Stability test & $\begin{array}{c}\text { Accuracy range } \\
\text { (\% bias) }\end{array}$ \\
\hline \multirow{4}{*}{ Fenbendazole } & Stock solution stability & $-11.2 \div+13.2$ \\
\cline { 2 - 3 } & Freeze-thaw stability & $-10.2 \div+13.0$ \\
\cline { 2 - 3 } & Short-term stability & $-8.1 \div+10.7$ \\
\cline { 2 - 3 } & Post-preparative stability & $-11.5 \div+10.7$ \\
\cline { 2 - 3 } & Long-term stability & $-9.2 \div+8.0$ \\
\hline \multirow{5}{*}{ Albendazole } & Stock solution stability & $-11.0 \div+12.4$ \\
\cline { 2 - 3 } & Freeze-thaw stability & $-4.9 \div+8.9$ \\
\cline { 2 - 3 } & Short-term stability & $-12.6 \div+9.3$ \\
\cline { 2 - 3 } & Post-preparative stability & $-6.8 \div+8.7$ \\
\cline { 2 - 3 } & Long-term stability & $-6.6 \div+10.3$ \\
\hline \multirow{5}{*}{ Albendazole sulfoxide } & Stock solution stability & $-4.4 \div+13.2$ \\
\cline { 2 - 3 } & Freeze-thaw stability & $+4.2 \div+11.4$ \\
\cline { 2 - 3 } & Short-term stability & $+4.4 \div+12.6$ \\
\cline { 2 - 3 } & Post-preparative stability & $-3.0 \div+12.7$ \\
\cline { 2 - 3 } & Long-term stability & $-2.8 \div+9.8$ \\
\hline
\end{tabular}

Stock solutions of analytes and internal standard were stable for 48 hours at $5^{\circ} \mathrm{C}$. Plasma samples were stable at $-20^{\circ} \mathrm{C}$ for at least 30 days, while at room temperature they were stable for a minimum of 6 hours. Processed plasma samples were stable in the autosampler for 18 hours when kept thermostatted at $20^{\circ} \mathrm{C}$. Stability of analytes during thawing and freezing of plasma samples was proven for at least two cycles (freezing at $20^{\circ} \mathrm{C}$, thawing to room temperature, then freezing them back to $-20^{\circ} \mathrm{C}$ ).

\section{Dilution integrity}

The results are presented in Table 7. The 10 times dilution of a 600 $\mathrm{ng} / \mathrm{ml}$ sample proved to be with acceptable accuracy and precision, both between-runs and within-run.

Table 7. Average accuracy, precision within and between runs for dilution integrity testing of fenbendazole, albendazole and albendazole sulfoxide dilution factor of 10 from $600 \mathrm{ng} / \mathrm{ml}, \mathrm{n}=5$

\begin{tabular}{|c|c|c|c|}
\hline \multirow{2}{*}{ Analyte } & $\begin{array}{c}\text { Dilution } \\
\text { integrity test }\end{array}$ & $\begin{array}{c}\text { Avg. accuracy } \\
\text { (\% bias) }\end{array}$ & $\begin{array}{c}\text { Avg. precision } \\
\text { (\% RSD) }\end{array}$ \\
\hline \multirow{2}{*}{ Fenbendazole } & Within runs & -2.7 & 3.6 \\
\cline { 2 - 4 } & Between runs & 1.4 & 7.5 \\
\hline \multirow{2}{*}{ Albendazole } & Within runs & -0.1 & 3.3 \\
\cline { 2 - 4 } & Between runs & -2.6 & 9.5 \\
\hline \multirow{2}{*}{ Albendazole sulfoxide } & Within runs & 1.9 & 8.2 \\
\cline { 2 - 4 } & Between runs & -11.7 & 9.8 \\
\hline
\end{tabular}




\section{Matrix effect}

As it can be seen in the results shown in Table 8, the internal standard (IS) normalized matrix effect (MF), calculated as the ratio of matrix factors of the analytes and the MF of the internal standard, and the relative standard deviation for IS normalized matrix factors proved that there is minimal effect of matrix (regardless if human or ovine plasma is used) on the final results.

Table 8. Matrix effect for fenbendazole, albendazole and albendazole sulfoxide

\begin{tabular}{|c|c|c|}
\hline Analyte & IS Normalized MF & $\begin{array}{c}\text { Coef. of variation } \\
\text { (\%) }\end{array}$ \\
\hline Fenbendazole & $0.969-1.051$ & $3.22-3.49$ \\
\hline Albendazole & $1.005-1.049$ & $1.94-2.20$ \\
\hline Albendazole sulfoxide & $0.954-1.027$ & $2.92-6.57$ \\
\hline
\end{tabular}

\section{Method comparison}

While there are a number of bioanalytical methods described in literature for the quantification of fenbendazole and albendazole, and/or their metabolites respectively [6-13], none have been reported for quantifying fenbendazole, albendazole and albendazole sulfoxide from both human and ovine plasma. While albendazole is rapidly metabolized after absorption to albendazole sulfoxide which is the main active metabolite, in the case of fenbendazole the metabolization to oxfendazole is reversible [1], thus for biomonitoring, drug-interaction, bioequivalence and other types of clinical and preclinical studies the measurement of plasma levels of fenbendazole, albendazole and albendazole sulfoxide are relevant. Studies have shown that fenbendazole achieves a maximum plasmatic concentration of $200 \mathrm{ng} / \mathrm{ml}$ in sheep after oral administration of a typical dose of $5 \mathrm{mg} / \mathrm{kg}$ fenbendazole [16], while albendazole sulfoxide can reach maximum plasmatic concentrations of up to $1950 \mathrm{ng} / \mathrm{ml}$ after oral administration of a typical dose of $7.5 \mathrm{mg} / \mathrm{kg}$ albendazole [17]. In humans after oral administration of $400 \mathrm{mg}$ of albendazole a rapid metabolization was shown to take place as albendazole concentration reach a peak concentration of around $100 \mathrm{ng} / \mathrm{ml}$ after a very short time [18] with albendazole sulfoxide being the main metabolite measurable in plasma and achieving plasmatic concentrations between $465 \mathrm{ng} / \mathrm{ml}$ and $909 \mathrm{ng} / \mathrm{ml}$ [19]. It is important to note that in the case of some kinds of studies, such as drug-drug interaction studies, metabolization of albendazole can be significantly decreased leading to higher plasmatic concentrations of albendazole and lowering the concentration of albendazole sulfoxide in the plasma. The lower limit 
of quantification for each analyte was chosen in order meet the criteria described in guidelines for bioanalytical method validation (to be at least $5 \%$ of the maximum plasmatic concentration expected to be measured). In case of concentrations above the upper limit of quantification samples can be diluted with a dilution factor of 10 in order the obtain concentrations within the limits of the calibration curves.

Compared to classical HPLC methods with UV or fluorescence detection used by Bistoletti et al., Rummel et al. and Shaikh et al. [11-13], liquid chromatography coupled with tandem mass spectrometry offers superior selectivity as well as better sensitivity.

Chhonker et al. [6] developed and fully validated a highly selective method for quantifying albendazole and its metabolites from human plasma, however the sample preparation uses solid phase extraction which is more labor intensive and involves higher costs per sample compared to the protein precipitation used in the present work. The total runtime for each sample is also shorter for our method, considerably reducing not only analysis time in the case of multiple study samples but also the total analytical costs. Other methods described in literature, such as the ones described by Zu et al. and Zhang et al. [9-10], use liquid-liquid extraction for sample purification which is also time consuming and more labor intensive compared to protein precipitation.

The method developed by the research team lead by Bach [7] is able to quantify oxfendazole from human plasma reliably and selectively, and can be used in pharmacokinetic studies similarly to the method developed by our research team which quantifies fenbendazole. The method developed by Bach et al. [7] also uses a simple and inexpensive protein precipitation technique for sample purification, however the total runtime for each sample is longer when compared to our method, which in the case of clinical pharmacokinetic studies involving the analysis of large numbers of samples can add up and significantly increase total analysis time.

\section{CONCLUSIONS}

A simple, rapid, versatile, sensitive and selective method was successfully developed for the quantification of fenbendazole, albendazole and albendazole sulfoxide from both human and ovine plasma. The method requires small amounts of biological samples as well as easy and fast sample preparation.

The method was validated in accordance with current EMA (European Medical Agency) and FDA (Federal Drug Administration) guidelines, for use in bioavailability studies in humans and sheep and it thus easily applicable in biomonitoring, bioequivalence, drug interaction studies. 


\section{EXPERIMENTAL SECTION}

\section{Reagents}

Fenbendazole, albendazole and albendazole sulfoxide reference substances were acquired from LGC Standards (Dr. Ehrenstorfer - Augsburg, Germany), fluconazole reference substance was acquired from the European Pharmacopoeia. HPLC grade acetonitrile and formic acid were acquired from VWR International (Radnor, USA). For the production of ultrapure water a Millipore Direct-Q 3 (Millipore - Milford, USA) system was used. Blank ovine blank plasma was provided by the University of Agriculture and Veterinary Medicine of Cluj-Napoca (Romania). Blank human plasma was provided by the local Transfusion Center in Targu-Mures (Romania). Both human and ovine blank plasma was collected in containers using K3EDTA as anticoagulant.

\section{Apparatus and equipment}

For chromatographic separation and detection an LC/MS system made up of an HPLC Perkin Elmer (Waltham, USA) FX-10 coupled with an AB Sciex (Framingham, USA) QTOF 4600 mass spectrometer was used. Other equipment used: Eppendorf (Hamburg, Germany) 5430R centrifuge; Partner Corporation (Bucharest, Romania) XA 523Y analytical scale; Velp Scientifica (Usmate Velate, Italy) vortex mixer; JP Selecta (Barcelona, Spain) Ultrasons H-D ultrasonic bath; Eppendorf Research Plus (Hamburg, Germany) pipettes.

\section{LC-MS/MS parameters}

Chromatographic separation of fenbendazole, albendazole, albendazole sulfoxide and fluconazole (internal standard - IS) was achieved using a Phenomenex Gemini NX-C18 HPLC column with dimensions 3.0 x $100 \mathrm{~mm}$ and $3 \mu \mathrm{m}$ particles, using a mobile phase composed of acetonitrile and aqueous $0.2 \%$ formic acid solution at a constant flow rate of $0.6 \mathrm{~mL} / \mathrm{min}$. Mobile phase gradient composition was $90 \%$ aqueous $0.2 \%$ formic acid and $10 \%$ acetonitrile between $0-2.3$ minutes, $60 \%$ aqueous $0.2 \%$ formic acid and $40 \%$ acetonitrile between $2.3-4.0$ minutes and $90 \%$ aqueous $0.2 \%$ formic acid and $10 \%$ acetonitrile between $4.0-5.0$ minutes.

Detection of analytes was carried out in selected reaction monitoring (SRM) mode by monitoring the following fragement ion $\mathrm{m} / \mathrm{z} 268.05$ from $\mathrm{m} / \mathrm{z}$ 300.08 at a collision energy (CE) of $33 \mathrm{~V}$ for fenbendazole; fragement ion $\mathrm{m} / \mathrm{z}$ $234.07 \mathrm{from} \mathrm{m} / \mathrm{z} 266.09$ at CE $25 \mathrm{~V}$ for albendazole and fragement ion $\mathrm{m} / \mathrm{z}$ $240.04 \mathrm{from} \mathrm{m} / \mathrm{z} 282.09$ at CE $25 \mathrm{~V}$ albendazole sulfoxide For the detection 
of the internal standard (fluconazole) fragement ion $\mathrm{m} / \mathrm{z} 220.06 \mathrm{from} \mathrm{m} / \mathrm{z}$ 307.60 at CE $19 \mathrm{~V}$ was monitored. The positive ionization of samples was performed using a heated electrospray ion source. The following ionization parameters were used for the ionization source: Spray voltage: 3500V, vaporizer temperature: $450{ }^{\circ} \mathrm{C}$, Ion Gas Source 1: 35, Ion Gas Source 2: 20, Curtain Gas: 10, Declustering Potential: 100. The volume injected of each solution into the LC-MS system was $5 \mu \mathrm{L}$ and the total sample run-time was 5 minutes per sample.

\section{Standard solutions}

Stock solution of fenbendazole, albendazole and albendazole sulfoxide in acetonitrile were prepared each having a concentration of $20 \mu \mathrm{g} / \mathrm{mL}$. Using these solutions, a stock mix solution in formic acid $0.2 \%$ was prepared having a concentration of $1 \mu \mathrm{g} / \mathrm{mL}$ for each analyte. This stock mix solution was used for the preparation of standard working solutions and quality control (QC) working solutions. Internal standard (IS) solution with a concentration of $5 \mu \mathrm{g} / \mathrm{mL}$ fluconazole in acetonitrile was prepared. Working solutions, IS solution and blank plasma were used to prepare plasma standard solutions with concentrations of $5,10,25,37.5,50,100,150$ and $250 \mathrm{ng} / \mathrm{mL}, 5 \mathrm{ng} / \mathrm{mL}$ being the lower limit of quantification - LLOQ for each analyte, and plasma QC samples with concentrations of $15 \mathrm{ng} / \mathrm{mL}$ (lower), $75 \mathrm{ng} / \mathrm{mL}$ (medium) and $175 \mathrm{ng} / \mathrm{mL}$ (upper) of each of the three analytes. In order to prepare these plasma standard and QC solutions $100 \mu \mathrm{L}$ of the appropriate working mix solution (in formic acid $0.2 \%$ ), $100 \mu \mathrm{L}$ blank plasma and $50 \mu \mathrm{L}$ IS solution $(5 \mu \mathrm{g} / \mathrm{mL}$ fluconazole) were mixed in Eppendorf tubes, finally adding $600 \mu \mathrm{L}$ acetonitrile. The mixture was vortexed for 2 minutes and centrifuged for 10 minutes at $12000 \mathrm{rpm}$. Supernatant was transferred to chromatographic vials to be injected into the LC-MS/MS system. The final concentration of the IS in plasma calibration standard solutions was $295 \mathrm{ng} / \mathrm{mL}$ fluconazole. Fluconazole was chosen as internal standard due to having the advantage of reduced cost compared to stable isotope labeled internal standards and validation of the method proved that it is adequate for use as the internal standard for the method proposed

\section{Sample preparation and analyte extraction}

In order to analyze plasma samples from bioavailability or biomonitoring studies the following method of analyte extraction and sample purification can be used: $100 \mu \mathrm{L}$ formic acid $0.2 \%, 100 \mu \mathrm{L}$ plasma sample and $50 \mu \mathrm{L}$ IS solution $(5 \mu \mathrm{g} / \mathrm{mL}$ fluconazole) are mixed in Eppendorf tubes, finally adding $600 \mu \mathrm{L}$ acetonitrile. After 2 minutes of vortexing and centrifugation for 10 minutes at 
$12000 \mathrm{rpm}$, the supernatant is transferred to a chromatographic vial and injected into the LC-MS/MS system.

\section{Method validation}

In order to assess the method selectivity, plasma samples spiked with the three analytes, with a concentration at the lower limit of quantification, and IS were analyzed and the obtained chromatograms were compared with chromatograms of six different blank plasma samples, three human and three ovine plasma.

The method was tested for carry-over effect by injecting a blank sample after a high concentration plasma calibration standard sample (250 $\mathrm{ng} / \mathrm{mL}$ ) in each run of the validation process and monitoring if analyte peaks appear in the blank solutions.

The mathematical model used for calibration curves was the internal standard calibration method with a linear fit, using 1/y2 weighting factor.

Accuracy and precision were tested by analyzing five quality control samples $(n=5)$, at four different levels of concentrations corresponding to LLOQ and QCs samples. Accuracy or bias\% (the relative difference between obtained and theoretical concentration) and precision or relative standard deviation, RSD\%, were determined for samples analyzed in the same analytical run and in different analytical runs.

The dilution process was studied with regards to accuracy and precision by preparing samples with a concentration of $600 \mathrm{ng} / \mathrm{mL}$, above upper limit of quantification (ULOQ) of $250 \mathrm{ng} / \mathrm{mL}$, which were then diluted, with a dilution factor of 10 , with blank plasma to a concentration of $60 \mathrm{ng} / \mathrm{mL}$, a value within the calibration curve. Accuracy and precision of diluted samples was calculated both between runs as well as within one analytical run in order to determine the integrity of the dilution.

Recovery of the analytes as well as the effect of the matrix on analyte measurements were investigated by processing and analyzing six low concentration and six high concentration quality control samples which were prepared in three of each human plasma and ovine plasma, and one lower and one high concentration quality control sample prepared in purified water. Ratios of peak areas obtained in the presence and the absence of matrix for the analytes and IS was determined to asses the recovery. The matrix factor (MF), calculated as the ratio between the peak areas in the presence of matrix and in the absence of matrix, for both the analytes and internal standard were calculated. Next, the relative standard deviation of the IS normalized matrix factors (ratio of MF of the analyte and MF of the internal standard) was calculated for all three analytes from both lower and high concentration quality samples. 
To test the stability of the analytes under different conditions quality control samples processed for stability testing were compared to freshly prepared quality control samples. Average concentration for each analyte at each concentration level needed to be within $85 \%$ and $115 \%$ of nominal concentration in order to asses stability of the analytes.

Stability of stock solution of the analyte mixture and internal standard solution was tested by analyzing quality control samples prepared using stock solutions and IS solution prepared previously and kept at $5^{\circ} \mathrm{C}$ for 48 hours before use. QCA and QCC samples, four of each solution, were prepared and analyzed in order to study the stability of the stock solutions.

Freeze-thaw stability was studied by analyzing quality control samples at two concentrations (QCA and QCC), by mixing $100 \mu \mathrm{L}$ working solution with $100 \mu \mathrm{L}$ blank plasma. These samples were prepared at the start of the validation process and were frozen and thawed twice (two cycles). During each cycle samples were frozen and kept in the freezer at $-20^{\circ} \mathrm{C}$ for approximately 20 hours then thawed and kept at room temperature for approximately 4 hours. After repeating this cycle twice, the samples were processed and analyzed.

Short-term stability at room temperature was studied analyzing quality control samples at two concentration levels (QCA and QCC), by mixing $100 \mu \mathrm{L}$ working solution with $100 \mu \mathrm{L}$ blank plasma. These samples were prepared and were kept at room temperature for 6 hours before being processed and analyzed.

Post-preparative stability in the autosampler was studied analyzing five quality control samples (five of each) at three concentration levels: QCA, QCB and QCC. These control samples were prepared and used for withinrun accuracy and precision testing then left in the autosampler for 18 hours thermostatted at a constant temperature of $20^{\circ} \mathrm{C}$, after which they were reinjected and analyzed.

Long-term stability was studied by analyzing quality control samples at two concentrations (QCA and QCC), by mixing $100 \mu \mathrm{L}$ working solution with $100 \mu \mathrm{L}$ blank plasma. These samples were prepared and were, frozen and kept in the freezer $\left(-20^{\circ} \mathrm{C}\right)$ for 30 days, after which they were thawed, processed and analyzed.

\section{ACKNOWLEDGMENTS}

This study was financed through Doctoral Research Grant no. 1680/3/19.01.2018 provided by the "luliu Hatieganu" University of Medicine and Pharmacy Cluj-Napoca.

Special acknowledgement goes to the Center for Advanced Medical and Pharmaceutical Research of the "George Emil Palade" University of Medicine, Pharmacy, Sciences, and Technology Targu Mures for the support offered in carrying out the study. 


\section{REFERENCES}

1. Committe for Medicinal Products for Veterinary Use. CVMP assessment report for Panacur AquaSol (EMEA/V/C/002008/X/0003).

https://www.ema.europa.eu/en/documents/variation-report/panacur-aquasol-vc-2008-x-03-epar-assessment-report-extension_en.pdf [retrieved November 2nd 2020]

2. P. Gao; C.V. Dang; J. Watson; J Am Assoc Lab Anim Sci., 2008, 47(6), 37-4

3. Committe For Veterinary Medicinal Products. Summary Report for Netobimin (EMEA/MRL/556/99-FINAL). https://www.ema.europa.eu/en/documents/mrlreport/netobimin-summary-report-2-committee-veterinary-medicinalproducts_en.pdf [retrieved November 2nd 2020]

4. World Health Organization model list of essential medicines: 21st list 2019. (WHO/MVP/EMP/IAU/2019.06). https://apps.who.int/iris/bitstream/handle/10665/325771/WHO-MVP-EMP-IAU2019.06-eng.pdf?sequence=1\&isAllowed=y [accessed November 2nd 2020]

5. Z. Wu; D. Lee; J. Joo; J.H. Shin; W. Kang; S. Oh; D.Y. Lee; S.J. Lee; S.S. Yea; H.S. Lee; T. Lee; K.H. Liu; Antimicrob. Agents Chemother., 2013, 57(11), 54485456

6. Y.S. Chhonker; C. Edi; D.J. Murry; J Pharm Biomed Anal., 2018, 151, 84-90

7. T. Bach; S. Bae; R. D'Cunha; P. Winokur; G. An; J Pharm Biomed Anal., 2019, 171, 111-117

8. J. Lakritz; D. Linden; D.E. Anderson; T.A. Specht; Vet Med. (Auckl), 2015, 6, 71-81

9. X. Zhu; S. Wang; Q. Liu; Q. Xu; C. Zhang; S. Xu; X. Wang; D. Li; H. Hu; J. AOAC Int, 2011, 94(3), 839-846

10. X. Zhang; H. Xu; H. Zhang;Y. Guo; Z. Dai; X. Chen; Anal Bioanal Chem, 2011, 401, 727-734

11. M. Bistoletti; L. Moreno; L. Alvarez; C. Lanusse; Food Chem., 2011, 126, 793-800

12. N. Rummel; I. Chung; B. Shaikh; J Liq Chromatogr Relat Technol., 2011, 34(18), 2211-2223

13. B. Shaikh; N. Rummel; R. Reimschuessel; J Agric Food Chem., 2003, 51, $3254-$ 3259

14. Guidance for Industry. Bioanalytical Method Validation. U.S. Department of Health and Human Services Food and Drug Administration Ce nte $r$ for Drug Evaluation and $\operatorname{Re} s$ earch (CDER)Center for Veterinary Medicine (CVM). https://www.fda.gov/media/70858/download [accesed November 2nd 2020]

15. Guideline on bioanalytical method validation. European Medicines Agency. Committe for Medicinal Products for Human Use (CHMP). 275542/2014. https://www.ema.europa.eu/en/documents/scientific-guideline/guidelinebioanalytical-method-validation_en.pdf [accessed November 2nd 2020] 
16. H.A. Benchaoui; Dose titration and efficacy studies with the combination fenbendazolepiperonyl butoxide in sheep, in Factors Affecting the Pharmacokinetics, Metabolism and Efficacy of Anthelmintic Drugs; ProQuest LLO, Ann Harbor, USA, 2018, Chapter 4, page 87

17. H.A. Benchaoui; Effect of piperonyl butoxide on the pharmacokinetics of albendazole and fenbendazole in sheep and goats, in Factors Affecting the Pharmacokinetics, Metabolism and Efficacy of Anthelmintic Drugs; ProQuest LLO, Ann Harbor, USA, 2018, Chapter 3, page 65

18. L. Ceballos; A. Krolewiecki; M. Juarez; L. Moreno; F. Schaer; L.I. Alvarez; R. Cimino; J. Walson; C.E. Lanusse; PLoS Negl Trop Dis., 2018, 12(1), e0005945

19. A. Mirfazaelian; S. Dadashzadeh; M.R. Rouini; Eur J Clin Pharmacol., 2002, 58, 403-408. 